\title{
Polymer based packaging of silicon pressure sensors in the oral cavity
}

\author{
Stöhr, Ingmar \\ TU Darmstadt, Institut EMK \\ Merckstr. 25, 64283 Darmstadt
}

\begin{abstract}
In this paper we describe a novel polymer based packaging of silicon pressure sensors for use in the oral cavity. The sensors are part of a wireless sensor system for measuring the spatially resolved pressure of the tongue against the hard palate. The packaging consist of a hard (Shore D80) UV-curing epoxy resin for protection of the bond wires during mounting of the sensor system and a soft (Shore A55) UV-curing acrylic urethane as encapsulation to achieve a watertight packaging with smooth surface. The packaged sensors are tested for change in sensitivity due to the encapsulation, for stability in wet environments, for creep due to viscoelastic behaviour of the encapsulation and dynamic sensor response.
\end{abstract}

\section{Introduction}

For orthodontists and speech therapists the knowledge of the tongue position and also magnitude and distribution of the pressure of the tongue against the upper palate are a key to diagnosis and therapy. Our goal is to develop a wireless sensor system, which records the spatially resolved static and dynamic tongue pressure. The measurement system consists of a central signal conditioning and data acquisition circuit, a telemetry module a lithium polymer battery and eight piezoresistive absolute silicon pressure sensors (SM5108, Silicon Microstructures, USA). A first prototype of the wireless sensor system [1] is shown in Figure 1.

Silicon pressure sensors have the advantage of a robust sensor output especially if compared to capacitive sensors and they are available in a broad range of configurations. In the following, we will present the specific requirements for this application, we will discuss the state of the art and will then present our novel approach for the packaging. Sensor characteristics of interest are shown and an outlook on further research is given.

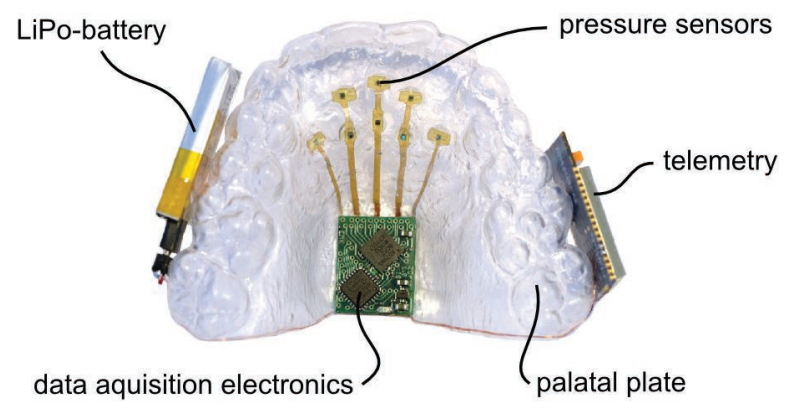

Fig. 1: Wireless sensor system for measuring the spatially resolved tongue pressure.

\section{Requirements}

Measurement of tongue pressure is not a common measurement task. Tongue pressure is a distributed force, normal to the palate and can therefore be seen as pressure comparable e.g. to the force distribution between foot and floor. That means contrary to typical pressure sensor application there are direct mechanical loads acting on the sensors. It can not be guaranteed, that the sensor is always loaded isostatic. That poses restrictions on the packaging of the sensors. Further requirements evolve from the request for minimal interference with the normal behaviour of the patients tongue. Table 1 lists some of the important requirements regarding the sensors and their packaging. 
Table 1: Requirements for the sensors in the wireless sensor system.

\begin{tabular}{|l|l|l|}
\hline Requirement & Value & Comment \\
\hline dimensions & $3 \mathrm{~mm}$ diameter & \\
\hline thickness & $<1.5 \mathrm{~mm}$ & better $<1 \mathrm{~mm}$ \\
\hline measuring range & $-50 \ldots+200 \mathrm{mbar}$ & relative to ambient pressure \\
\hline resolution & $1 \mathrm{mbar}$ & \\
\hline uncertainty of measurement & $1 \%$ & \\
\hline resistance to saliva & 1 hour & \\
\hline
\end{tabular}

Since the sensors are mounted in individual palatal plates opposed to an invariable package, there are further requirements regarding the mounting process. The tongue is very sensible to hard edges. To avoid increased irritation of the patient, the surface has to be as smooth as possible. Therefore, the final encapsulation of the sensing elements should be done after mounting them into the palatal plate. Since every palate has its unique shape, the mounting has to be performed manually. Therefore, some kind of protection of the very sensible bond wires is required to prevent them from damage during the mounting process. Only one sensor at a time can be encapsulated, because otherwise the liquid encapsulation material will not stay in place due to the three dimensional shape of the palate, thus a fast curing material is to be preferred. To avoid further stresses due to mismatch in thermal expansion coefficient, the curing should take place at room temperature. The viscosity of the liquid encapsulation material should not be to low to allow the formation of a dome above the sensor. For a good pressure transmission the cured encapsulation should be as soft as possible, but to prevent damage of the packaging during handling of the system, certain hardness is of advantage. Since the sensors are for use in the oral cavity, the encapsulation should preferably be certified and bio-compatible.

\section{State of the art}

State of the art for industrial piezoresistive pressure sensors are oil filled packages with a steel membrane. They offer excellent long term stability. But commercially available sensors can not match the dimensions required for this application. Another disadvantage is the steel membrane. To allow for good pressure transmission its thickness is in the range of 20 to $100 \mu \mathrm{m}$ [2]. Therefore, it is very sensible to point loads and contact to sharp objects.

Another known solution for protection of piezoresistive pressure sensors is to encapsulate them in polymers [2]. Due to the high diffusion constant of polymers $\left(10^{-7}\right.$ to $\left.10^{-5} \mathrm{~cm}^{2} / \mathrm{s}\right)$ a $1 \mathrm{~mm}$ thick coating of silicone can only protect the sensor for minutes to hours, before the concentration of water inside the encapsulation reaches $50 \%$ of the concentration outside [3]. With thin metal coatings (diffusion constant $10^{-18} \mathrm{~cm}^{2} / \mathrm{s}$ ) some ten to hundred years of protection can easily be achieved. Therefore, organic encapsulations are mainly used in low-cost applications or were dry and non-corrosive gases are being measured.

The encapsulation has two functions. It has to protect the metal parts of the sensor e.g. the metallization layer, the bond pads and bond wires from corrosion. On the other hand it has to transmit the pressure signal to the sensing element [2]. For this application corrosion is not as relevant as for industrial sensors. Normal use of the system in clinical research would be one ore two hours of use and then about a week of rest and therefore ample time to release absorbed water. Also the system will only have to work for a relatively short period like a year.

The main problems to be expected with a polymer based packaging are creep due to viscoelastic behaviour of the encapsulation and changes of sensor characteristics due to absorption of water. These are systematic errors which can not be easily compensated for.

\section{Novel packaging}

To fulfil the requirements regarding mounting and surface of the sensors, a two stage packaging was developed. The sensing elements are mounted on a flexible printed circuit board. Electrical connection is done by wire bonding with $25 \mu \mathrm{m}$ aluminium wires. The first step of the packaging process protects the bond wires from mechanical damage. This is achieved with a hard chip underfill. We choose EleosolPanacol Vitralit 1605, a UV-curing epoxy resin with a hardness of Shore D80. This is manually applied around the sensing element and under the bond wires. Through capillary action the underfill fills-up the whole space between board an bond wires. After UV-curing the underfill supports the bond wires. Lightly 
touching the palatal plate during the mounting process will no longer destroy the wires. The underfill also serves as a protection during use of the system, in case some sharp edge (e.g. a fingernail) is pressed in the encapsulation. Figure 2 shows a sensing element with bond wires and underfill in place.

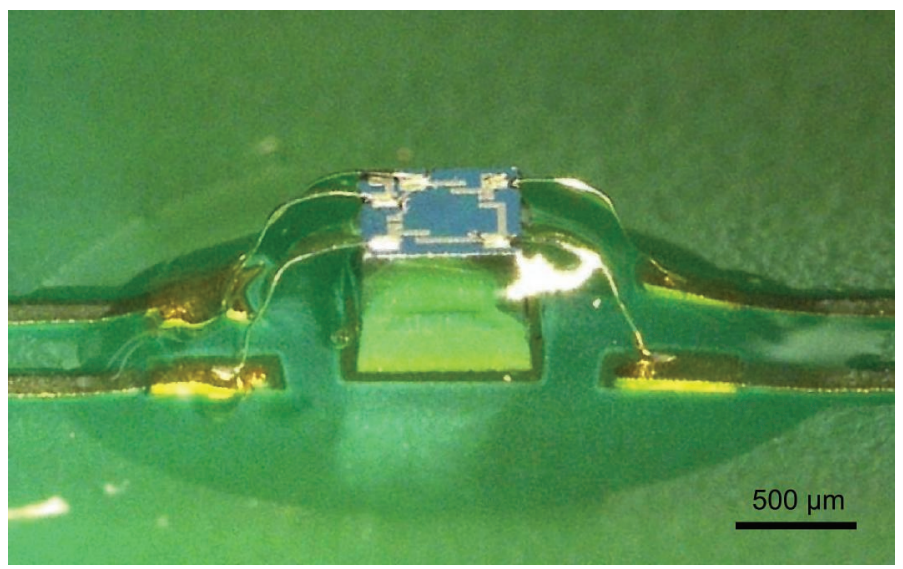

Fig. 2: Sensing element mounted on PCB with Al-wire bonds and Vitralit 1605 underfill.

In this stage the sensing element is mounted into the palatal plate from the backside. Afterwards the final encapsulation is done with a soft material. This ensures a watertight encapsulation and a smooth surface. Figure 3 shows the whole process of packaging and mounting the sensing elements into the palatal plate.
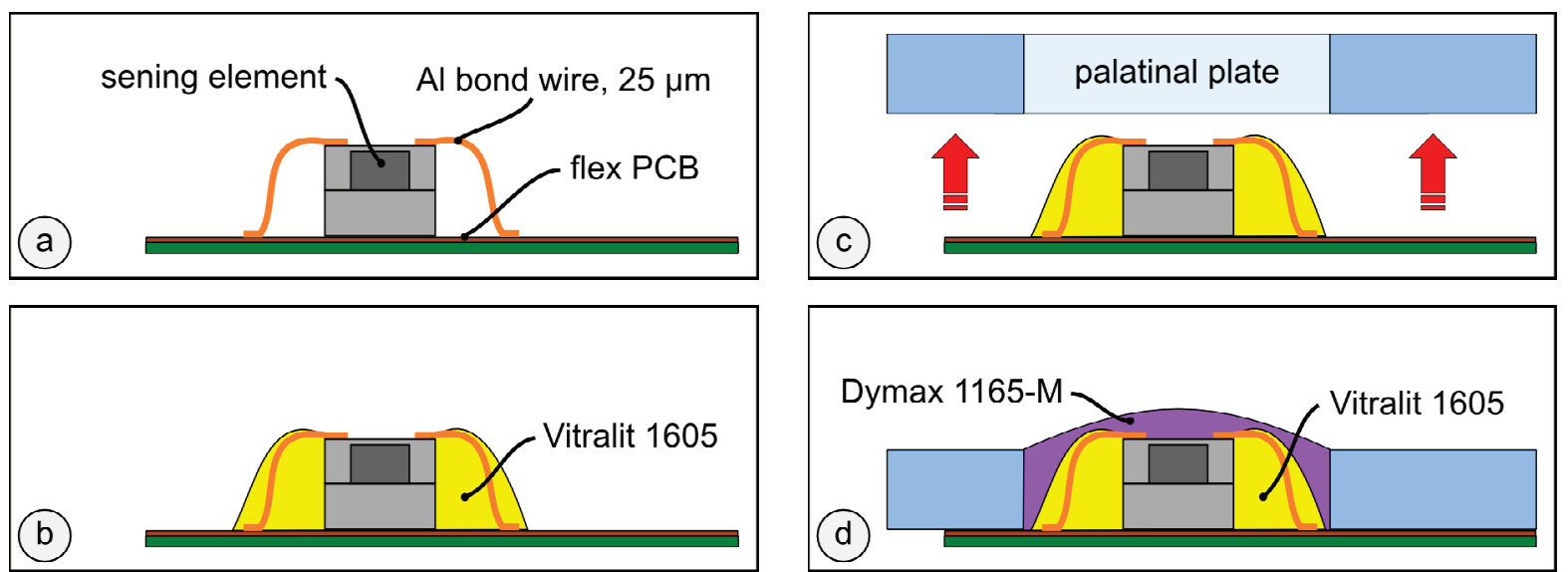

Fig. 3: Developed two stage packaging process.

a) sensing element mounted on flex PCB and contacted with $25 \mu \mathrm{m} \mathrm{Al}$-wires

b) protection of the bond wires by UV-curing epoxy resin

c) mounting of the sensing element into the palatal plate

d) encapsulation with UV-curing acrylic urethane

For the soft encapsulation eleven biocompatible materials were examined regarding processing, change in sensitivity and offset drift under mechanical loads [4]. For most examined materials the viscosity is to high for the proper application. First experiments showed no significant difference in the transmission behaviour of Dymax 1165-M and Vitralit 5140. Because of the more suitable viscosity, the Dymax material was chosen for further use.

\section{Measurement setup}

Change in sensitivity due to encapsulation, behaviour after exposition to water, creep and response to short pressure pulses were examined. For this purpose the sensing elements are mounted on a standard FR4 printed circuit board with instant adhesive (Henkel Loctite 4011). Electrical connection is achieved with $25 \mu \mathrm{m}$ aluminium bond wires. Bond wires are protected as described above with Vitralit 1605 . The 
palatal plate is simulated by a $0.5 \mathrm{~mm}$ thick piece of ABS thermoplastic. Afterwards the sensing element is encapsulated with Dymax 1165-M. Figure 4 shows a sample of the so achieved packaging.

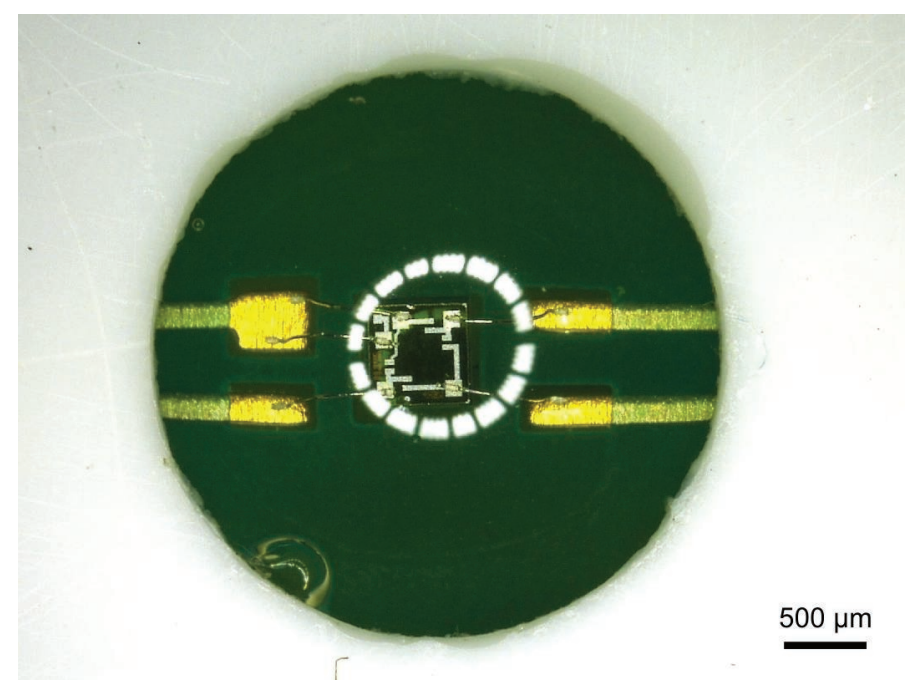

Fig. 4: Packaged sensing element for determining the sensor characteristics (white dots in the centre are a light-source).

The sensors are mounted in a pressure vessel which is connected to a PPC2 pressure source. Pressure medium is dry air. The sensing elements are connected to a National Instruments PXle-4330 bridge input module. The excitation voltage $(2.5 \mathrm{~V})$ is applied at least one hour prior to measurements to ensure a thermal steady state. Since a precise absolute pressure reference was not available at that time, the measurements are performed as fast as possible, to rule out any influence of changes in ambient pressure. Each pressure step is held for three minutes prior to measurement. Then the control of the pressure source is disabled to avoid any pressure steps during measurement. The bridge output is sampled with 1000 sps for two seconds. Mean value and standard derivation are then calculated and recorded on a PC running LabVIEW.

\section{Results}

\subsection{Change of sensitivity due to encapsulation}

Sensitivity is calculated according to equation 1 . Where $v_{0}$ is the bridge output at ambient pressure $p_{0}$ and $v_{1}$ the sensor output at the test pressure $p_{1}$ of 200 mbar. The sensor output is not measured as voltage, but as output voltage per excitation voltage ( $\mathrm{V}$ per $\mathrm{V})$.

$$
B_{0}=\frac{v_{1}-v_{0}}{p_{1}-p_{0}}
$$

Sensitivity of the sensing elements is measured after bond wire protection and again after complete encapsulation. Table 3 shows the results for the tested sensors. As expected, the sensitivity $\mathrm{B}_{0}$ is reduced by the encapsulation. The reduction is in the range of 4.7 to $6.4 \%$. The sensors remain sensitive enough and the change in sensitivity shows only a slight variation, which can possibly be explained by variations in the encapsulation thickness due to the manual process.

Table 3: Sensitivity of the sensors prior an after complete encapsulation with Dymax 1165-M.

\begin{tabular}{|c|c|c|c|}
\hline $\begin{array}{c}\text { Sensor } \\
\text { No. }\end{array}$ & $\begin{array}{c}\mathbf{B}_{\mathbf{0}} \text { before encapsulation } \\
\text { in V / (V mbar) }\end{array}$ & $\begin{array}{c}\mathbf{B}_{\mathbf{0}} \text { after encapsulation } \\
\text { in V / ( V mbar) }\end{array}$ & $\begin{array}{c}\text { change of } \mathbf{B}_{\mathbf{0}} \\
\text { in \% }\end{array}$ \\
\hline 1 & $1.873 \mathrm{e}-05$ & $1.752 \mathrm{e}-05$ & -6.44 \\
\hline 3 & $1.889 \mathrm{e}-05$ & $1.780 \mathrm{e}-05$ & -5.77 \\
\hline 5 & $1.899 \mathrm{e}-05$ & $1.795 \mathrm{e}-05$ & -5.48 \\
\hline 6 & $1.823 \mathrm{e}-05$ & $1.737 \mathrm{e}-05$ & -4.70 \\
\hline 7 & $1.877 \mathrm{e}-05$ & $1.774 \mathrm{e}-05$ & -5.48 \\
\hline 10 & $1.882 \mathrm{e}-05$ & $1.789 \mathrm{e}-05$ & -4.98 \\
\hline
\end{tabular}




\subsection{Influence of moisture on the packaging}

As mentioned before, a polymeric sensor packaging in principle is sensitive to humidity and moisture. To examine this effect, the packaged sensors were immersed into deionised water for one hour, which equals the expected time of use in the oral cavity. Sensitivity of the sensors was measured directly before and after contact to water. Table 5 shows the results. Figure 5 shows the sensitivity of sensor 5 recorded over 110 hours, starting right before the exposure to water.

Table 5: Sensitivity of the sensors prior an after 1 hour exposure to deionised water.

\begin{tabular}{|c|c|c|c|}
\hline $\begin{array}{c}\text { Sensor } \\
\text { No. }\end{array}$ & $\begin{array}{c}\mathbf{B}_{\mathbf{0}} \text { before water } \\
\text { in V / ( V mbar) }\end{array}$ & $\begin{array}{c}\mathbf{B}_{\mathbf{0}} \text { after water } \\
\text { in V / ( V mbar) }\end{array}$ & $\begin{array}{c}\text { change of } \mathbf{B}_{\mathbf{0}} \\
\text { in \% }\end{array}$ \\
\hline 1 & $1.775 \mathrm{e}-05$ & $1.783 \mathrm{e}-05$ & -0.43 \\
\hline 3 & $1.791 \mathrm{e}-05$ & $1.787 \mathrm{e}-05$ & 0.22 \\
\hline 5 & $1.822 \mathrm{e}-05$ & $1.828 \mathrm{e}-05$ & -0.34 \\
\hline 6 & $1.754 \mathrm{e}-05$ & $1.758 \mathrm{e}-05$ & -0.20 \\
\hline 7 & $1.787 \mathrm{e}-05$ & $1.784 \mathrm{e}-05$ & 0.17 \\
\hline 10 & $1.810 \mathrm{e}-05$ & $1.814 \mathrm{e}-05$ & -0.19 \\
\hline
\end{tabular}

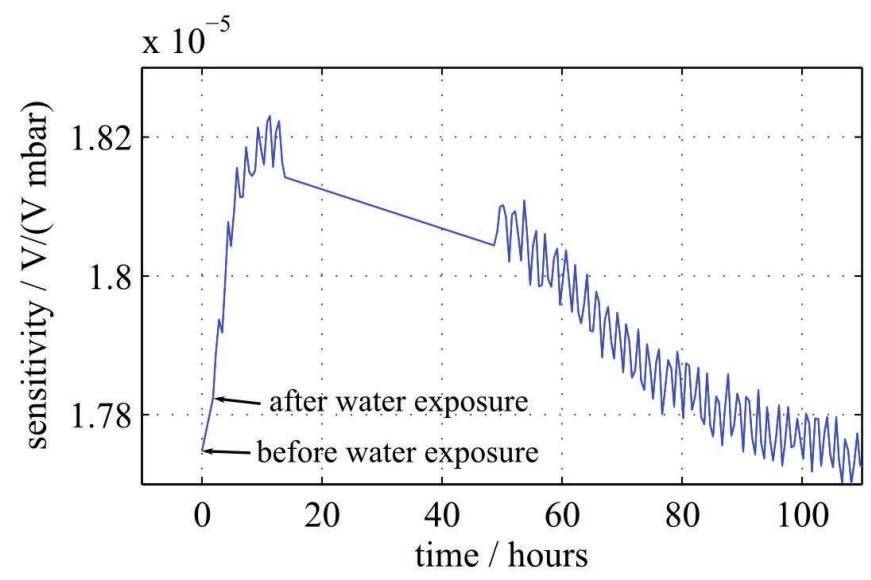

Fig. 5: Sensitivity of sensor 5 over $110 \mathrm{~h}$, starting right before $1 \mathrm{~h}$ exposure to deionised water.

The sensitivity change directly after one hour in water is at most $0.43 \%$, therefore enabling a measurement with acceptable errors during the first hour in water. After some time, the sensitivity shows a steep increase, even tough the sensors were already removed from the water, presumably because of the water diffusing deeper into the encapsulation. It takes about four and a half days for the sensors to settle to their normal sensitivity prior to immersion into water. Since the sensors stay mounted in the pressure vessel over the whole time, air exchange is only possible through the pressure source and therefore very limited.

Although the humidity in the lab was stable over weeks, the sensitivity of the sensors sometimes changed as much as $2.8 \%$ over days. This can only be explained by changes of humidity in the supply of compressed air since silica gel in the pressure vessel eliminated this behaviour.

\subsection{Creep due to viscoelastic behaviour of encapsulation}

Due to viscoelastic behaviour of the encapsulation the sensor shows some creep. Creep is measured by applying a pressure step from 0 mbar to 200 mbar. After 60 seconds, in which the pressure source is allowed to stabilize, the sensor output is recorded over time. Table 6 shows the results for the different sensors. After about 240 seconds the sensor output had reached a stable value. Maximum creep over 240 s ranges from $0.26 \%$ to $0.62 \%$.

Table 6: Creep after step of 200 mbar from ambient pressure (in \% of nominal value (200mbar)).

\begin{tabular}{|l|c|c|c|c|c|c|}
\hline Time & Sensor 1 & Sensor 3 & Sensor 5 & Sensor 6 & Sensor 7 & Sensor 10 \\
\hline $60 \mathrm{sec}$ & 0.29 & 0.15 & 0.21 & 0.17 & 0.17 & 0.26 \\
\hline $240 \mathrm{sec}$ & 0.62 & 0.26 & 0.41 & 0.34 & 0.32 & 0.51 \\
\hline
\end{tabular}




\subsection{Dynamic response of the packaged sensor}

Since not only static but also dynamic tongue pressures should be measured, the dynamic response of the packaging was investigated. Short pressure pulses with duration similar to a swallowing event were applied to the pressure vessel. Figure 6 shows a comparison between an unpackaged sensor (blue) and a packaged sensor (red). A low pass characteristic and the effect of creep can clearly bee seen. It is planed to measure the frequency response of the packaging with a dynamic pressure source [5].

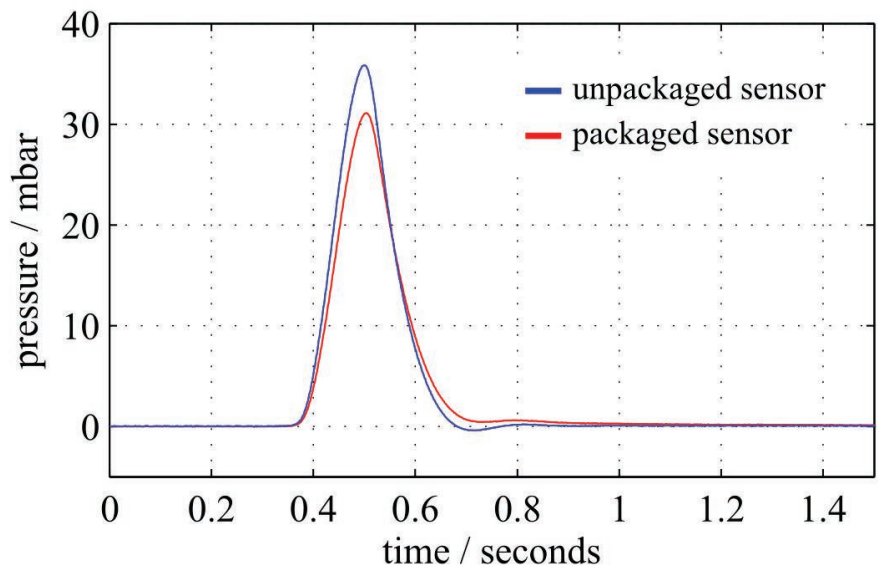

Fig. 6: Comparison between output of packaged and unpackaged sensor for a pressure pulse.

\section{Conclusion and outlook}

A novel polymer based packaging for piezoresistive pressure sensors is presented. The packaging takes into account some requirements specific to the application. Protection of the bond wires during the mounting process is achieved. The encapsulation only slightly reduces the sensibility of the sensors. Some creep can be observed and the packaging clearly shows low pass behaviour for dynamic pressures.

The packaging can guarantee proper function of the sensors for up to one hour in water, but is sensitive to long term changes in humidity. Therefore, either storing the sensor system in a dry environment (silica gel) or a further protective coating with parylene has to be investigated.

To be able to give a better representation of dynamic pressures the frequency response of the packaged sensors has to be quantified.

\section{Literature}

[1] Stöhr, I.; Manderscheid, M.; Schleußner, A.; Schuster, G.; Werthschützky, R.: System zur Erfassung des Zungendrucks mittels piezoresistiver Silizium-Drucksensoren. In: Gemeinsame Jahrestagung der Deutschen, Österreichischen und Schweizerischen Gesellschaften für Biomedizinische Technik, 05.-08. Okt. 2010, Rostock.

[2] Hohlfeld, O.: Miniaturisierte korrosionsfeste Gehäuse für Silizium-Drucksensoren. In: Fortschr.Ber. VDI Reihe 8 Nr. 878. Düsseldorf: VDI Verlag 2001

[3] Dyrbye, K. ; Brown, T. R. ; Eriksen, G. F.: Packaging of physical sensors for aggressive media applications. In: Journal of Micromechanics and Microengineering Bd. 6 (1996), Nr. 1

[4] Stöhr, I.; Manderscheid, M.; Werthschützky, R.: Neuartiges polymerbasiertes Packaging von Silizium-Druckmesselementen zum Einsatz in der Kieferorthopädie. In: 9. Dresdner SensorSymposium, Dresden 2009

[5] Kober, T.; Stöhr, I.; Sindlinger, S.; Werthschützky, R.: Analyzing amplitude and phase response of differential pressure sensors using a dynamic pressure source. In: Sensor+Test Conference 2009, 26-28 May 2009, Nürnberg. 